\title{
ESTIMATION OF THE ASCERTAINMENT PROBABILITY OF RARE DISEASES ${ }^{1}$
}

\author{
Norikazu YASUDA \\ Division of Genetics, National Institute of Radiological Sciences, \\ Chiba 260, Japan
}

\begin{abstract}
Summary Two models of ascertainment have been reviewed and maximum likelihood estimates of probabilities are given. Simple formulae were derived for the model of multiple sources of ascertainment per proband. Numerical tables were prepared for the model of proband distribution among affected siblings with illustrative examples. Discussions were made on the ascertainment probability pertaining to the indirect estimation of prevalence as well as incidence of rare diseases.
\end{abstract}

\section{INTRODUCTION}

For a common trait it is feasible and clearly desirable to estimate prevalence, defined as the number of cases of the trait existing in a given area at a given time, from a random sample of general population. However, this is not feasible or prohibitively expensive for the rare diseases with which a clinical geneticist often has to deal, since reliable estimates would require careful examination of a large fraction of the population. Such rare disorders are ordinarily ascertained through pedigrees which contain one or more probands, selected through hospital records, death certificates, inquiries to physicians, examination of a population sample, or other direct means of ascertainment, and, in addition, may contain secondary cases not represented in these primary sources and detected only through a family of probands. For this incomplete selection, several indirect estimates of prevalence are available, depending on the mode of inheritance and method of ascertainment.

The probability of ascertainment, $\pi$, is indispensable to evaluate prevalence as well as segregation frequency in incomplete selection (Barrai et al., 1965). Fisher (1934) studied the bias in segregation frequency derived through incomplete ascertainment, and devised a formula for the estimation of $\pi$, consequently correcting the bias in segregation frequency. Introducing a concept of proportion of sporadic cases, Morton (1959) has developed segregation models from which maximum likeihood solution of the probability of ascertainment is obtainable in aid of a computer. In practice however it is desirable to have a rather simpler procedure

Received June 2, 1979

${ }^{1}$ Supported in part by grants from Ministry of Health and Welfare, Japan. 
and is preferable to discern underlining assumptions in the segregation models.

In this communication, we shall provide not only analytical solutions for the maximum likelihood estimate of the probability of ascertainment, but also numerical tables for it. Attention confines to either population sample or a data set of sibships, not goes in pedigrees (Elston and Sobel, 1979; Thompson and Canning, 1979). Furthermore our discussion remains to assume that the probability of ascertainment is a constant although it is often impractical to define probands so that they are independent. Interested reader should consult for example Anderson (1961), Neel (1962), Fraser (1963) and Morton (1969).

\section{MODELS}

Model 1. Multiple sources of ascertainment per proband.

An estimate of $\pi$ may be obtained from the number of ascertainments per proband, provided a person can be ascertained in more than one independent way. If the number of sources such as hospital and/or institution be small, an adequate model might be sought as follows (Morton, 1962; Morton and Lindstein, 1976). Suppose that there are two independent sources, 1 and 2, with the ascertainment probabilities being $\pi_{1}$ and $\pi_{2}$, respectively. The expected proportion and the observed number of probands of ascertainment by source 1 alone, source 2 alone and both sources are respectively

$\begin{array}{ccc}\text { source } & \begin{array}{c}\text { expected } \\ \text { proportion }\end{array} & \begin{array}{c}\text { observed } \\ \text { number }\end{array} \\ 1 & \pi_{1}\left(1-\pi_{2}\right) / \pi & \mathrm{n}_{1} \\ 2 & \pi_{2}\left(1-\pi_{2}\right) / \pi & \mathrm{n}_{2} \\ 1 \text { and } 2 & \pi_{1} \pi_{2} / \pi & \mathrm{n}_{12} \\ \text { total } & 1 & \mathrm{n}\end{array}$

where $\pi=\pi_{1}+\pi_{2}-\pi_{1} \pi_{2}$. The maximum likelihood solutions and their standard errors are then

$$
\hat{\pi}_{1}=\frac{\mathrm{n}_{12}}{\mathrm{n}_{2}+\mathrm{n}_{12}} \pm \sqrt{\frac{\hat{\pi}(1-\hat{\pi}) \hat{\pi}_{1}}{\mathrm{n} \hat{\pi}_{2}\left(1-\hat{\pi}_{2}\right)}}
$$

and

$$
\hat{\pi}_{2}=\frac{n_{12}}{n_{1}+n_{12}} \pm \sqrt{\frac{\hat{\pi}(1-\hat{\pi}) \hat{\pi}_{2}}{n} \hat{\pi}_{1}\left(1-\hat{\pi}_{1}\right)}
$$

The overall probability of ascertainment $\pi$ is estimated as

$$
\hat{\pi}=\frac{\mathrm{nn}_{12}}{\left(\mathrm{n}_{1}+\mathrm{n}_{12}\right)\left(\mathrm{n}_{2}+\mathrm{n}_{12}\right)} \pm \sqrt{\frac{\hat{\pi}(1-\hat{\pi})\left[\hat{\pi}^{2}-(2-\hat{\pi}) \hat{\pi}_{1} \hat{\pi}_{2}\right]}{\mathrm{n} \hat{\pi}_{1} \hat{\pi}_{2}}}
$$

No degree of freedom is left for a test of goodness of fit. That is, independence of ascertainment between two sources cannot be tested by this model.

Numerical example. The Down's syndrom surveillance in Sweden, cited in Morton and Lindsten (1976), serves as an illustration. There were two sources 
in 1971 and 1972: The Swedish Register of Congenital Malformations (1) and Swedish Cytogenetic Register (2). Birth certificates (3) were added in 1973. In this example we shall pool (3) and (2). The overall distributions are $\mathrm{n}_{1}=52, \mathrm{n}_{2}=127$ and $\mathrm{n}_{12}=$ 231 which yield $\hat{\pi}_{1}=0.6453 \pm 0.0253, \hat{\pi}_{2}=0.8163 \pm 0.0230$ and $\hat{\pi}=0.9348 \pm 0.0094$. While the assumption of independence is in doubt, the probability of ascertainment, nevertheless, was high.

In general if there were $t$ independent sources of ascertainments, maximum likelihood solutions yield

$$
\hat{\pi}_{\mathrm{i}}=\mathrm{N}_{\mathrm{i}} / \mathrm{k}(\mathrm{i}=1,2, \ldots, \mathrm{t})
$$

where $\mathrm{N}_{\mathrm{i}}$ is the number of probands identified at the i-th source regardless of the number of ascertainment, and the nuisance parameter $\mathrm{k}$ satisfies the (t-1)-th order equation:

$$
\mathrm{k}^{\mathrm{t}-1}(\mathrm{k}-\mathrm{n})=\left(\mathrm{k}-\mathrm{N}_{1}\right)\left(\mathrm{k}-\mathrm{N}_{2}\right) \ldots\left(\mathrm{k}-\mathrm{N}_{\mathrm{t}}\right) .
$$

The elements of the information matrix $\mathrm{K}$ are

$$
\begin{gathered}
\mathrm{K}_{\mathrm{ii}}=\frac{\mathrm{n}}{\pi^{2} \pi_{\mathrm{i}}^{2}\left(1-\pi_{\mathrm{i}}\right)^{2}}\left[\mathrm{~A}_{\mathrm{i}} \pi^{2}\left(1-2 \pi_{\mathrm{i}}\right)-\pi_{\mathrm{i}}{ }^{2}(1-2 \pi)\right] \\
(\mathrm{i}=1,2, \ldots, \mathrm{t})
\end{gathered}
$$

and

$$
\mathrm{K}_{1 j}=-\frac{\mathrm{n}(1-\pi)}{\pi^{2}\left(1-\pi_{\mathrm{i}}\right)\left(1-\pi_{j}\right)}(\mathrm{i} \neq \mathrm{j}, \mathrm{i}, \mathrm{j}=1,2, \ldots, \mathrm{t})
$$

in which

$$
\mathrm{A}_{\mathrm{i}}=\frac{1-\pi}{\pi}\left[\frac{\pi_{\mathrm{i}}}{1-\pi_{\mathrm{i}}}+\frac{\pi_{\mathrm{i}} \pi_{\mathrm{j}}}{\left(1-\pi_{\mathrm{i}}\right)\left(1-\pi_{\mathrm{j}}\right)}+\ldots+\frac{\pi_{1} \pi_{2} \cdots \pi_{\mathrm{t}}}{1-\pi}\right]
$$

Thus the asymptotic variance of $\pi_{1}$ is the $\mathrm{i}$-th diagonal element of inverse of the information matrix. The overall ascertainment probability $\pi$ is estimated by

$$
\hat{\pi}=1-\left(1-\hat{\pi}_{1}\right)\left(1-\hat{\pi}_{2}\right) \ldots\left(1-\hat{\pi}_{t}\right)
$$

with the variance

$$
\mathrm{V}(\hat{\pi})=b_{1} \mathrm{~V}\left(\hat{\pi}_{1}\right)+b_{2} \mathrm{~V}\left(\hat{\pi}_{2}\right)+\ldots+b_{t}\left(\hat{\pi}_{t}\right)
$$

where $b_{i}=\left[(1-\hat{\pi}) /\left(1-\hat{\pi}_{i}\right)\right]^{2}$. There are degrees of freedom for the test of goodness of fit; namely, $\mathrm{df}=2^{\mathrm{t}}-\mathrm{t}-2$.

For $t=3$ the equation (4) yields

$k=\frac{2 N_{1} N_{2} N_{3}}{N_{1} N_{2}+N_{1} N_{3}+N_{2} N_{3}-\sqrt{\left(N_{1} N_{2}+N_{1} N_{3}+N_{2} N_{3}\right)^{2}-4 N_{1} N_{2} N_{3}\left(n_{12}+n_{13}+n_{23}+2 n_{123}\right)}}$

where, for example, $\mathrm{N}_{1}=\mathrm{n}_{1}+\mathrm{n}_{12}+\mathrm{n}_{13}+\mathrm{n}_{123}$ and the degrees of freedom are left by three. That is the surveillance program in future should use at least three sources since three degrees of freedom are left for a test of independence among sources. 
Numerical example. The following hypothetical example may illustrate the computational procedures. Suppose that three institutions have joined a surveillance program for a certain anomaly (say, chromosome aberrations) in a population. The following scores were observed: $\mathrm{n}_{1}=6, \mathrm{n}_{2}=14, \mathrm{n}_{3}=84, \mathrm{n}_{12}=4, \mathrm{n}_{13}=22, \mathrm{n}_{23}=$ 56 and $\mathrm{n}_{123}=14$ so that $\mathrm{n}=200, \mathrm{~N}_{1}=6+4+22+14=46, \mathrm{~N}_{2}=88$ and $\mathrm{N}_{3}=176$. From (9) we obtain $k=222$ since $\mathrm{N}_{1} \mathrm{~N}_{2} \mathrm{~N}_{3}=712,448, \mathrm{~N}_{1} \mathrm{~N}_{2}+\mathrm{N}_{1} \mathrm{~N}_{3}+\mathrm{N}_{2} \mathrm{~N}_{3}=27,632$ and $n_{12}+n_{13}+n_{23}+2 n_{123}=110$. Then we have from (3) $\hat{\pi}_{1}=N_{1} / k=46 / 222=0.207$ $\hat{\pi}_{2}=88 / 222=0.396$ and $\hat{\pi}_{3}=176 / 222=0.793$, and from (7) $\hat{\pi}=0.901$. The elements of information matrix are, from (5), $\mathrm{K}_{11}=1,313, \mathrm{~K}_{12}=\mathrm{K}_{21}=-51, \mathrm{~K}_{13}=\mathrm{K}_{31}=-149$, $\mathrm{K}_{22}=861, \mathrm{~K}_{23}=\mathrm{K}_{32}=-195$ and $\mathrm{K}_{33}=782$. The diagonal elements of the inverse of K-matrix are respectively $\mathrm{V}\left(\hat{\pi}_{1}\right)=(0.028)^{2}, \mathrm{~V}\left(\hat{\pi}_{2}\right)=(0.035)^{2}$ and $\mathrm{V}\left(\hat{\pi}_{3}\right)=(0.037)^{2}$ so that from (8) $V(\tilde{\pi})=(0.015)^{2}$. The chi-square value for a test of goodness of fit is 0.06 with three degress of freedom, which is not significant. Namely, three institutions with the ascertainment probability respectively $\hat{\pi}_{1}=0.207 \pm 0.028, \hat{\pi}_{2}=$ $0.396 \pm 0.035$ and $\hat{\pi}_{3}=0.793 \pm 0.037$ have been monitoring independently on the anomaly with the overall ascertainment probability $\hat{\pi}=0.901 \pm 0.015$. In reality, however, the ascertainment of probands is seldomly independent of institutions for the same diseases.

As an alternative a simple approximation is provided by the truncated Poisson distribution which arises when there is an indefinitely large number of independent sources, each with a constant ascertainment probability (Morton, 1959). Let us suppose that mean number of independent ascertainment per proband be $m$. Then $\pi=1-\exp (-\mathrm{m})$ and the distribution of $t$ ascertainments per proband is

$$
\mathrm{P}(\mathrm{t})=\frac{[-\ln (1-\pi)]^{\mathrm{t}}(1-\pi)}{\mathrm{t} !}
$$

with the scores of maximum likelihood

$$
\mathrm{U}=\frac{1}{1-\pi}\left[\left(\sum \mathrm{ta}_{\mathrm{t}}\right) \frac{\pi}{-\ln (1-\pi)}-\left(\sum \mathrm{a}_{\mathrm{t}}\right)\right]
$$

and

$$
\mathrm{K}=\frac{\left(\sum \mathrm{a}_{\mathrm{t}}\right)[-\pi / \ln (1-\pi)-(1-\pi)]}{[\pi(1-\pi)]^{2}}
$$

where $a_{t}$ is the number of proband who was ascertained independently $t$ times. The solution of the maximum likelihood equation, $U=0$, satisfies

$$
\frac{-\ln (1-\hat{\pi})}{\hat{\pi}}=\frac{\sum t a_{t}}{\sum a_{t}}
$$

where the right hand of the equation is the mean number $(\mathrm{m})$ of independent ascertainments per proband. In appendix Table Al is prepared for solving the equation (13), tabulated the value of $-\ln (1-\pi) / \pi$ for $\pi=0.00$ through 0.99 with the increment 0.01 .

Numerical example. Tanaka and Watanabe (1967) have reported on the 
Table A1. Mean number of ascertainment per proband: $[-\ln (1-\pi)] / \pi$.

\begin{tabular}{l|ccccccccccc}
\hline$\pi$ & 0.00 & 0.01 & 0.02 & 0.03 & 0.04 & 0.05 & 0.06 & 0.07 & 0.08 & 0.09 & $\pi$ \\
\hline 0.0 & 1.00000 & 1.00503 & 1.01014 & 1.01531 & 1.02055 & 1.02587 & 1.031 .26 & 1.03672 & 1.04227 & 1.04790 & 0.0 \\
0.1 & 1.05361 & 1.05940 & 1.06528 & 1.07125 & 1.07731 & 1.08346 & 1.08971 & 1.09606 & 1.10251 & 1.10906 & 0.1 \\
0.2 & 1.11572 & 1.12249 & 1.12937 & 1.13637 & 1.14349 & 1.15073 & 1.15810 & 1.16560 & 1.17323 & 1.18100 & 0.2 \\
0.3 & 1.18892 & 1.19698 & 1.20520 & 1.21357 & 1.2221 .0 & 1.23081 & 1.23969 & 1.24874 & 1.25799 & 1.26743 & 0.3 \\
0.4 & 1.27706 & 1.28691 & 1.29697 & 1.30725 & 1.31777 & 1.32853 & 1.33954 & 1.35080 & 1.36235 & 1.37417 & 0.4 \\
0.5 & 1.38629 & 1.39873 & 1.41148 & 1.42457 & 1.43802 & 1.45183 & 1.46604 & 1.48065 & 1.49569 & 1.51118 & 0.5 \\
0.6 & 1.52715 & 1.54362 & 1.56062 & 1.57818 & 1.59633 & 1.61511 & 1.63456 & 1.65472 & 1.67564 & 1.69737 & 0.6 \\
0.7 & 1.71996 & 1.74349 & 1.75801 & 1.79361 & 1.82037 & 1.84839 & 1.87778 & 1.90867 & 1.94119 & 1.97550 & 0.7 \\
0.8 & 2.01180 & 2.05029 & 2.09122 & 2.13489 & 2.18164 & 2.23191 & 2.28618 & 2.34508 & 2.40939 & 2.48008 & 0.8 \\
0.9 & 2.55843 & 2.64609 & 2.74536 & 2.85942 & 2.99299 & 3.15340 & 3.35300 & 3.61501 & 3.99186 & 4.65169 & 0.9 \\
\hline
\end{tabular}

Table 1. Ascertainment distribution of albinism in the eastern Shizuoka prefecture (Tanaka and Watanabe, 1967).

\begin{tabular}{lccc}
\hline $\mathrm{t}$ & obs. & exp. & chi-square \\
\hline 1 & 2 & 2.38 & 0.06 \\
2 & 1 & 2.47 & 0.88 \\
3 & 5 & 1.71 & 6.32 \\
$\geqq 4$ & 0 & 1.44 & 1.44 \\
& & & $8.69^{*}$ \\
\hline
\end{tabular}

$\mathrm{t}=$ number of ascertainment per proband $\hat{\pi}=0.875 \pm 0.071$

* Significant at $5 \%$ level $(\mathrm{df}=2)$.

number of ascertainments without identifying the sources on albino probands in the eastern part of Shizuoka prefecture of Japan. Table 1 depicts the distribution, from which mean number of ascertainment per proband is $\sum \mathrm{ta}_{\mathrm{t}} / \sum \mathrm{a}_{\mathrm{t}}=(1 \times 2+$ $2 \times 1+3 \times 5) /(2+1+5)=2.3750$. From Table A1 $\hat{\pi}=0.87$ is the estimated probability of ascertainment. Substituting it for (12), we have $K=8 \times[(1 / 2.3750)-$ $0.13] /[0.87 \times 0.13]^{2}=182.0219$ which yields the standard error $0.07(=\sqrt{1 / K})$. The maximum likelihood solution is in fact $0.875 \pm 0.071$ in the accuracy of three decimal places. This estimate however might be overrating since the value of the chisquare for the goodness of fit was significant at five percent level $\left(\chi^{2}=8.69\right.$ with of $=$ $2)$, though the number of observations was small in each class, thereby, the assumption of independence would not be fulfilled. Excess of probands in the class where probands were ascertained three times is responsible for not being significant.

Model 2. Sibship materials.

Any person in a sibship who is independently ascertained of the other members of sibship will be called a proband. A sibship with $r$ affected may contain 
from 1 to $r$ probands. Let the actual number of probands be a, the distribution of $\mathrm{a}$ is

$$
\mathrm{P}(\mathrm{a}, \mathrm{r})=\frac{{ }_{\mathrm{r}} \mathrm{C}_{\mathrm{a}} \pi^{\mathrm{a}}(1-\pi)^{\mathrm{r}-\mathrm{a}}}{1-(1-\pi)^{\mathrm{r}}} \quad(\mathrm{a}=1,2, \ldots, \mathrm{r})
$$

in which $\pi$ is the probability of ascertainment of affected persons. Note here that simplex sib $(r=a=1)$ yields no information about $\pi$. The observed distribution of sibships with $r$ affected persons, among whom a sibs are probands, is indispensable and is customarily called the $R A$ table.

Let $n_{r a}$ be the observed number of sibships with $r$ affected and a probands in the sample. Taking Fisher's estimate as a trial one $\left(\pi_{0}\right)$; namely,

$$
\pi_{0}=\frac{\sum \mathrm{a}(\mathrm{a}-1) \mathrm{n}_{\mathrm{ra}}}{\sum \mathrm{a}(\mathrm{r}-1) \mathrm{n}_{\mathrm{ra}}} \quad \text { (Fisher, 1934) }
$$

the maximum likelihood solution may be obtained from

$$
\hat{\pi}=\pi_{0}+\mathrm{U} / \mathrm{K}
$$

with the standard error $\sqrt{1 / \mathrm{K}}$. In which the scores are given by

$$
\mathrm{U}=\left[\mathrm{A}-\sum_{\mathrm{r}} \mathrm{A}_{\mathrm{r}} \mathrm{n}_{\mathrm{r}}\right] /[\pi(1-\pi)]
$$

and

$$
\mathrm{K}=\sum_{\mathrm{r}} \mathrm{B}_{\mathrm{r}} \mathrm{n}_{\mathrm{r}} /[\pi(1-\pi)]^{2}
$$

where $A=\sum_{a=1}^{r} a n_{r a}$, or the total number of probands, and $n_{r}=\sum_{a=1}^{r} n_{r a}$, or the number of sibs with $r$ affected persons. The value of $A_{r}$ and $B_{r}$ are respectively tabulated for $\pi=0.01$ through 1.00 with the increment 0.01 and $r=2$ through 15 by the following formulae;

$$
A_{r}=r \pi /\left[1-(1-\pi)^{r}\right]
$$

and

$$
\mathrm{B}_{\mathrm{r}}=\mathrm{A}_{\mathrm{r}}(1-\pi)\left[1-\mathrm{A}_{\mathrm{r}}(1-\pi)^{\mathrm{r}-1}\right]
$$

Note that $A_{1}=1$ and $B_{1}=0$. Elandt-Johnson (1971) presented the formula (17) and (18) for the estimation of segregation frequency.

Numerical example. Furusho and Yasuda (1973) have reported on the distribution of 860 probands among congenital deaf born to normal parents in Kanto district of Japan, which is shown in Table 2. Since $\sum \mathrm{a}(\mathrm{a}-1) \mathrm{n}_{\mathrm{ra}}=2 \times 84+2 \times 11+$ $6 \times 4+2 \times 3+6 \times 2+2=234$, and $\sum \mathrm{a}(\mathrm{r}-1) \mathrm{n}_{\mathrm{ra}}=108+2 \times 84+2 \times 24+4 \times 11+6 \times 4+$ $3 \times 7+6 \times 3+9 \times 2+4 \times 2+10=467$, we have $\pi_{0}=234 / 467=0.50$. We also have $\mathrm{A}=\sum \mathrm{an}_{\mathrm{ra}}=614+108+2 \times 84+24+2 \times 11+3 \times 4+7+2 \times 3+3 \times 2+2+2 \times 1=971$. For $\pi=0.5$, Table $\mathrm{A} 2$ gives $\mathrm{A}_{2}=1.33333, \mathrm{~A}_{3}=1.71429, \mathrm{~A}_{4}=2.13333, \mathrm{~A}_{5}=$ 2.58065 and $A_{6}=3.04762$ so that $\sum_{r=1}^{6} A_{r} n_{r}=614+1.33333 \times 192+1.71429 \times 39+$ 


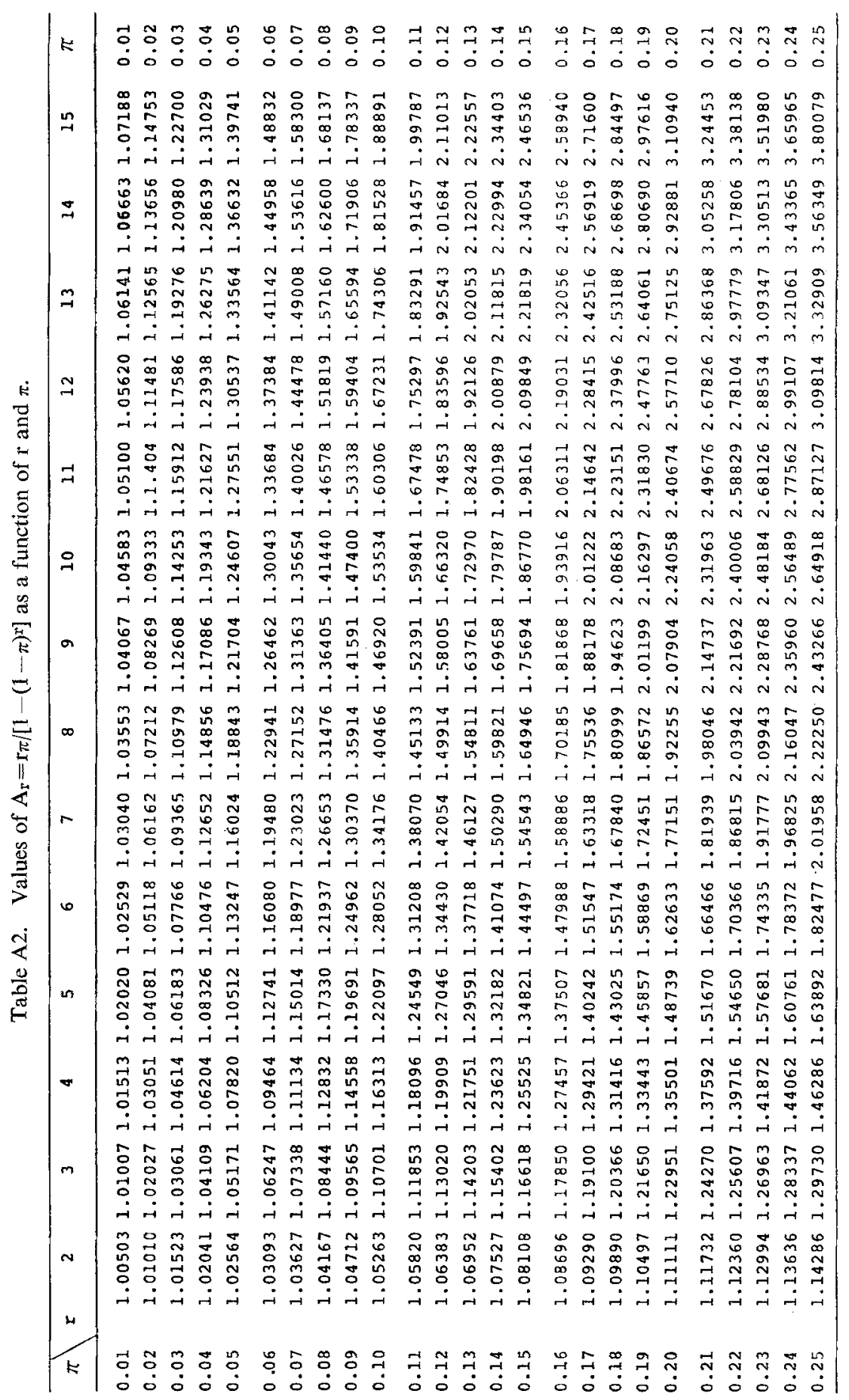




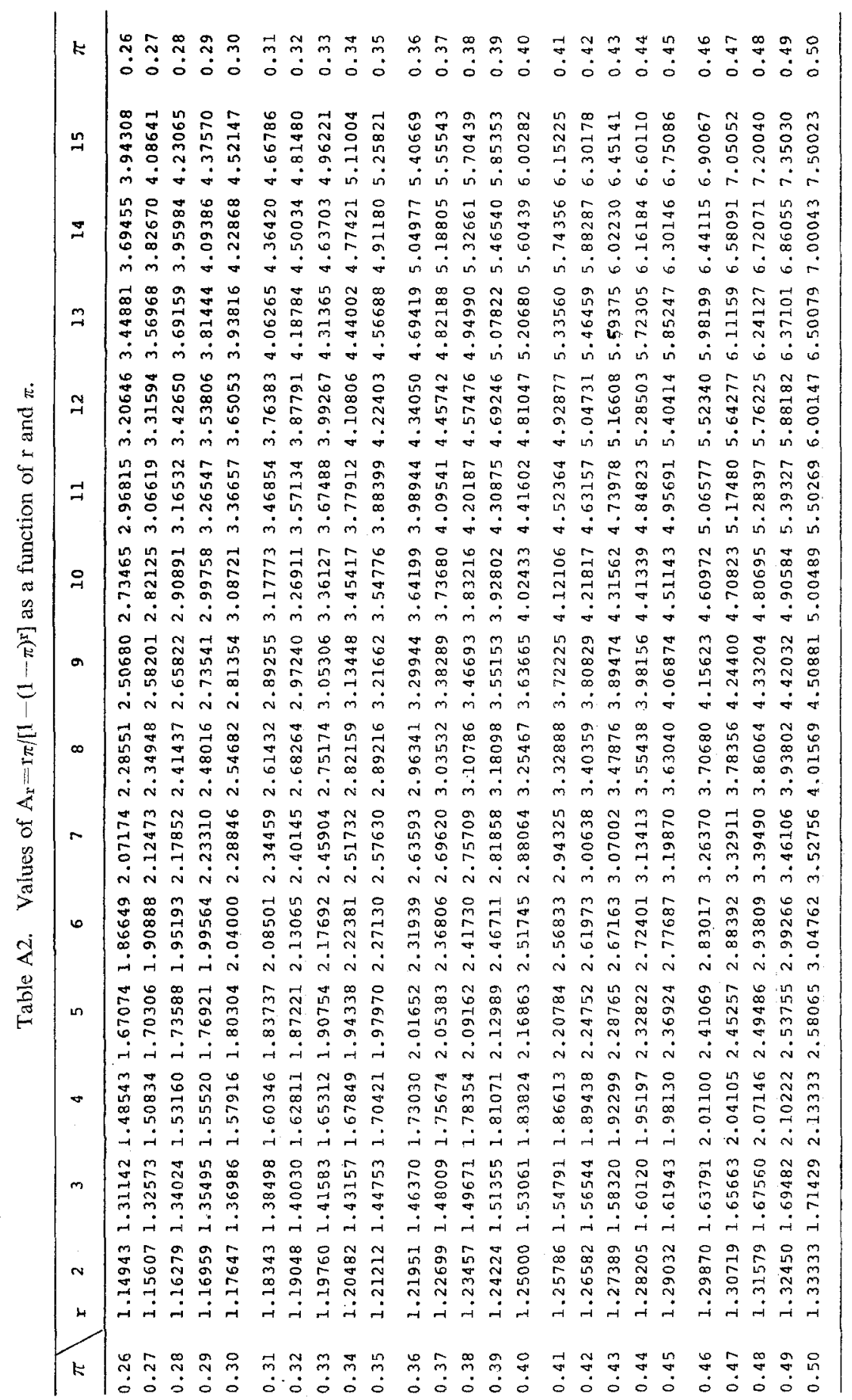




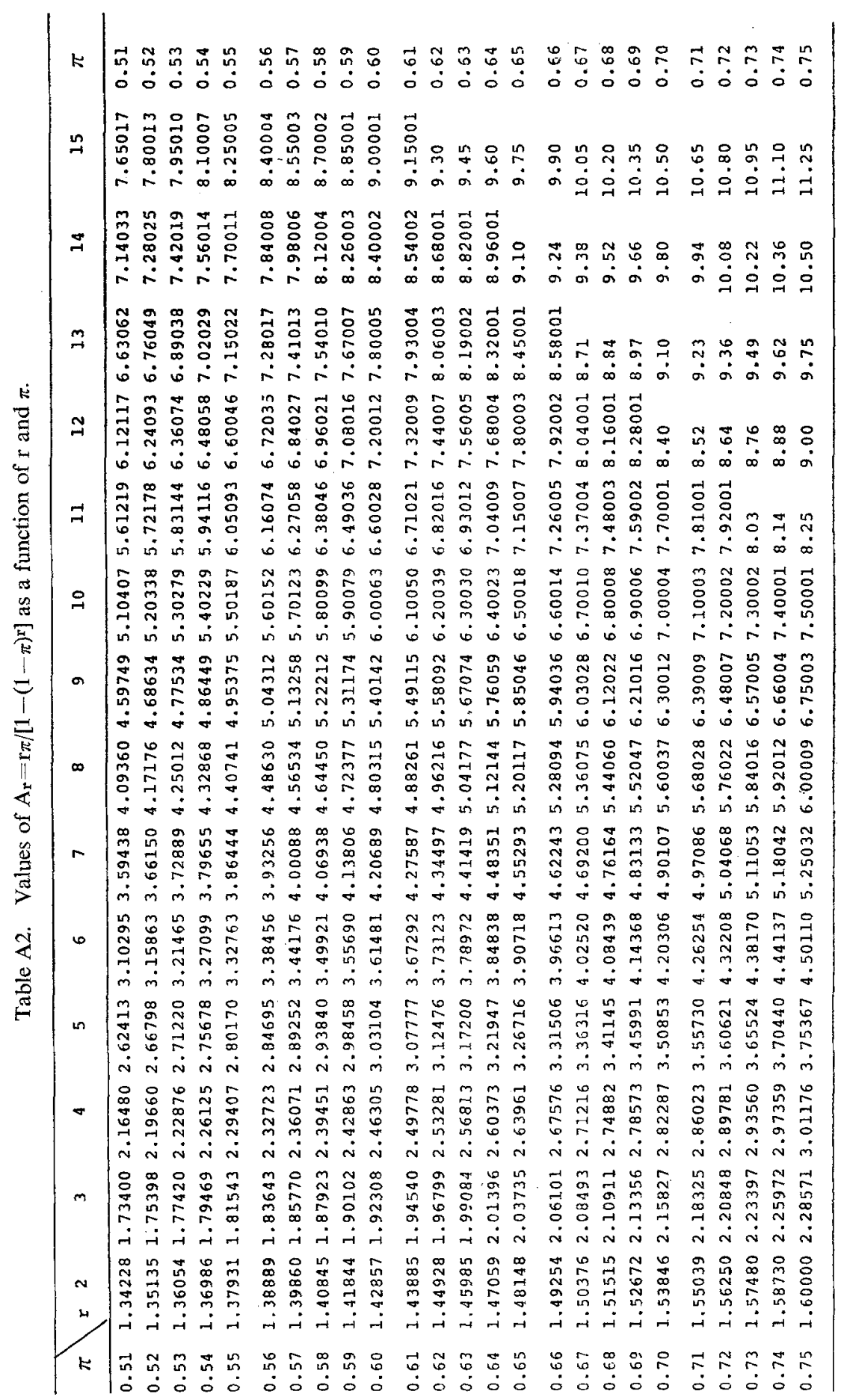




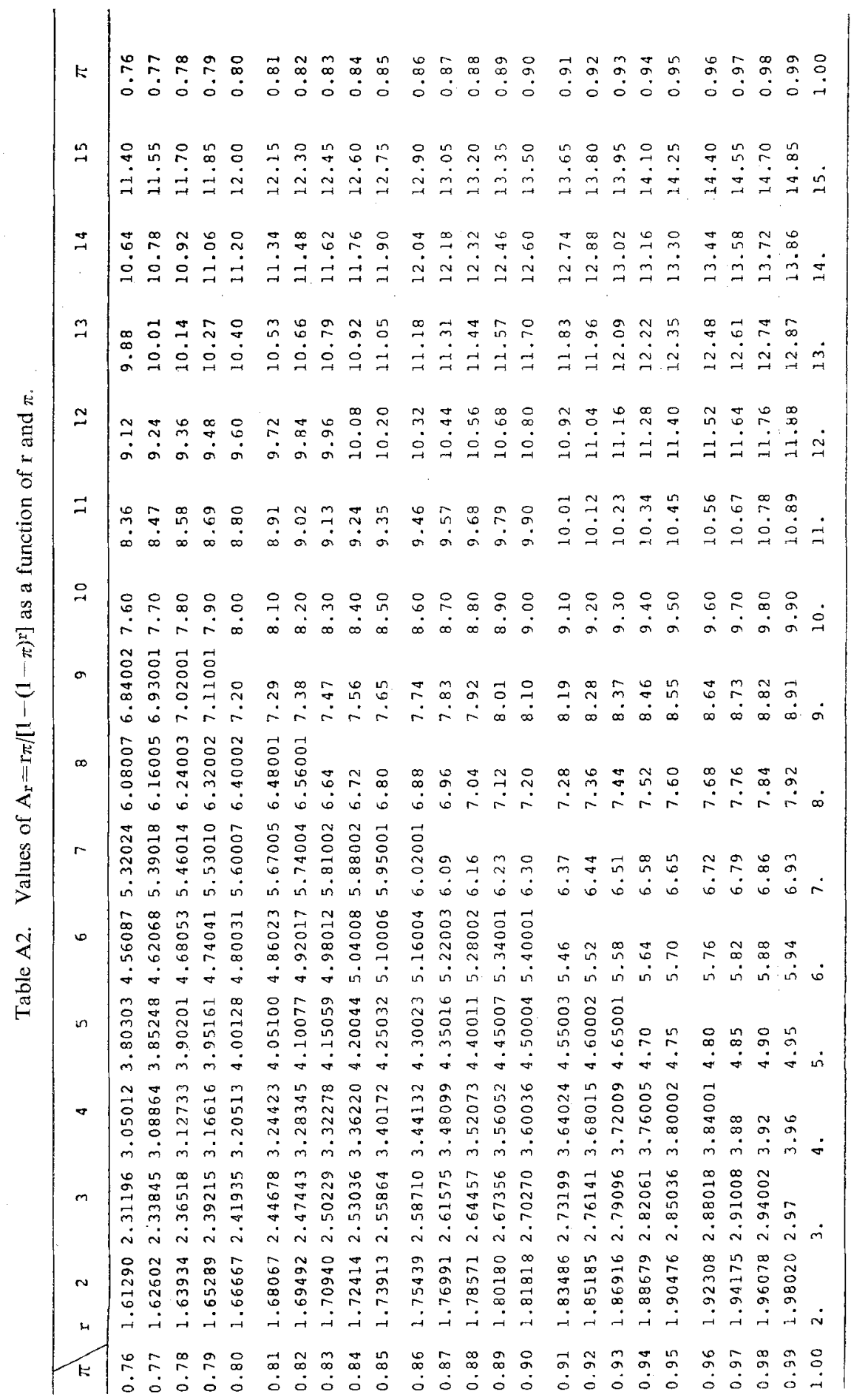




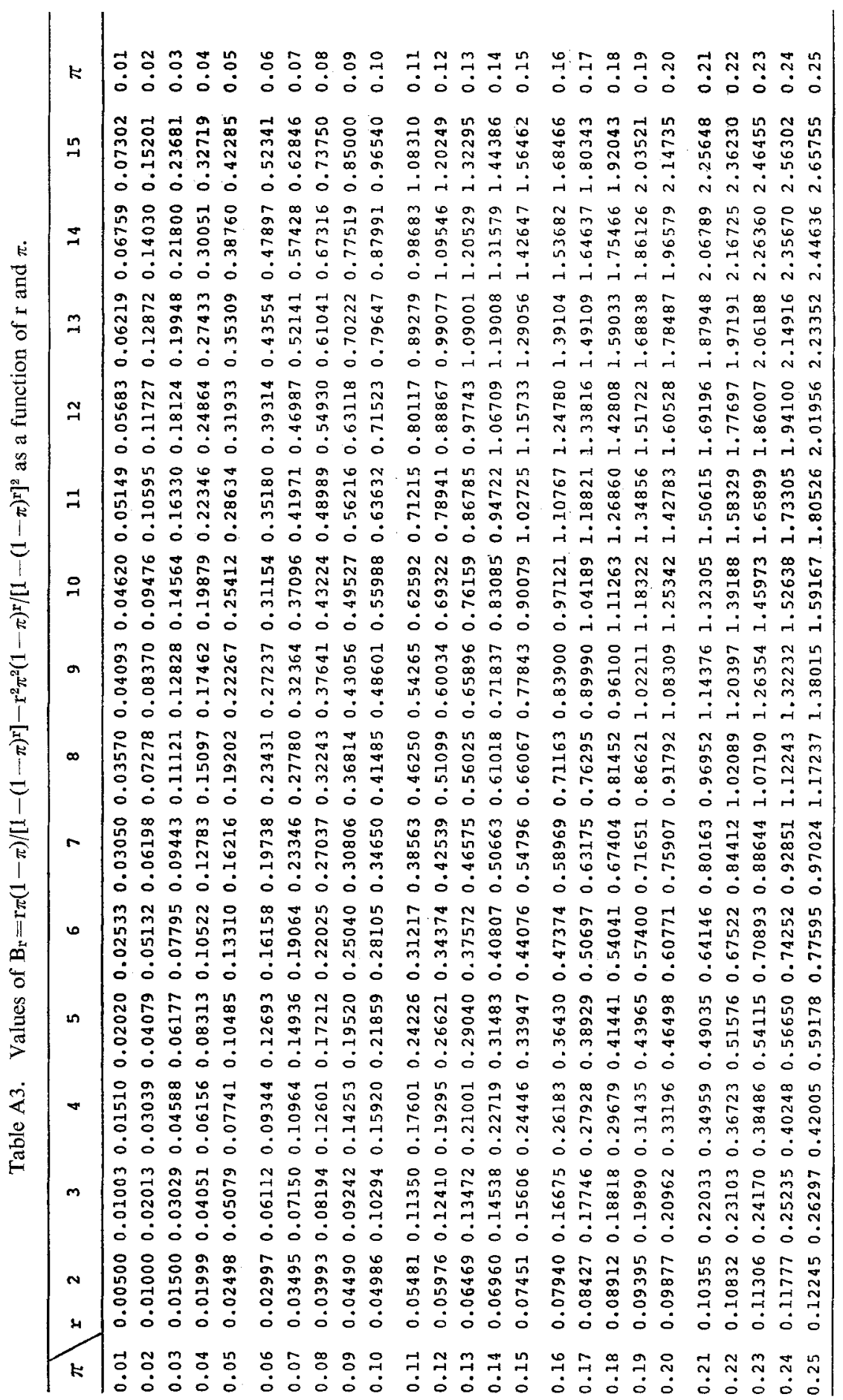




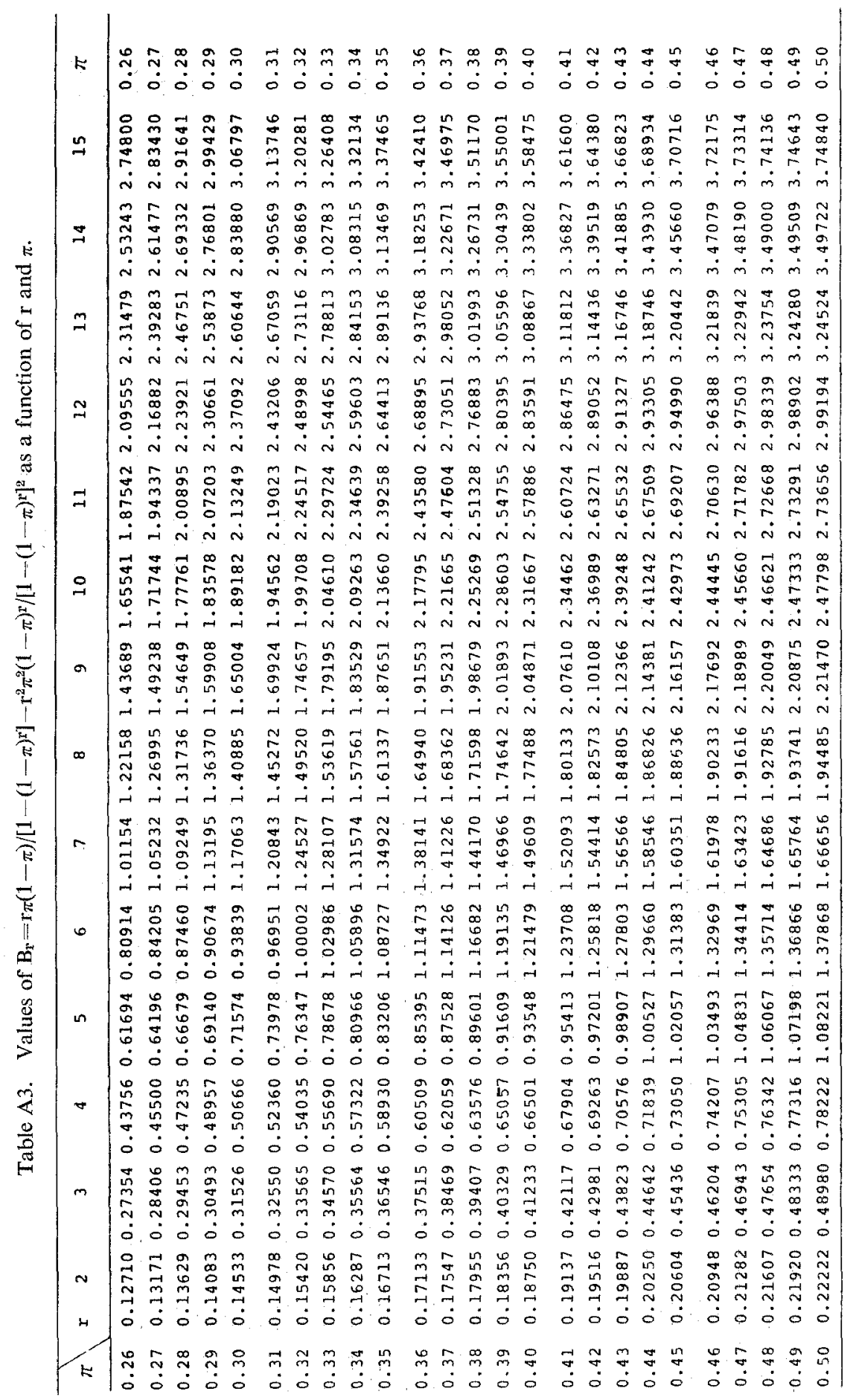




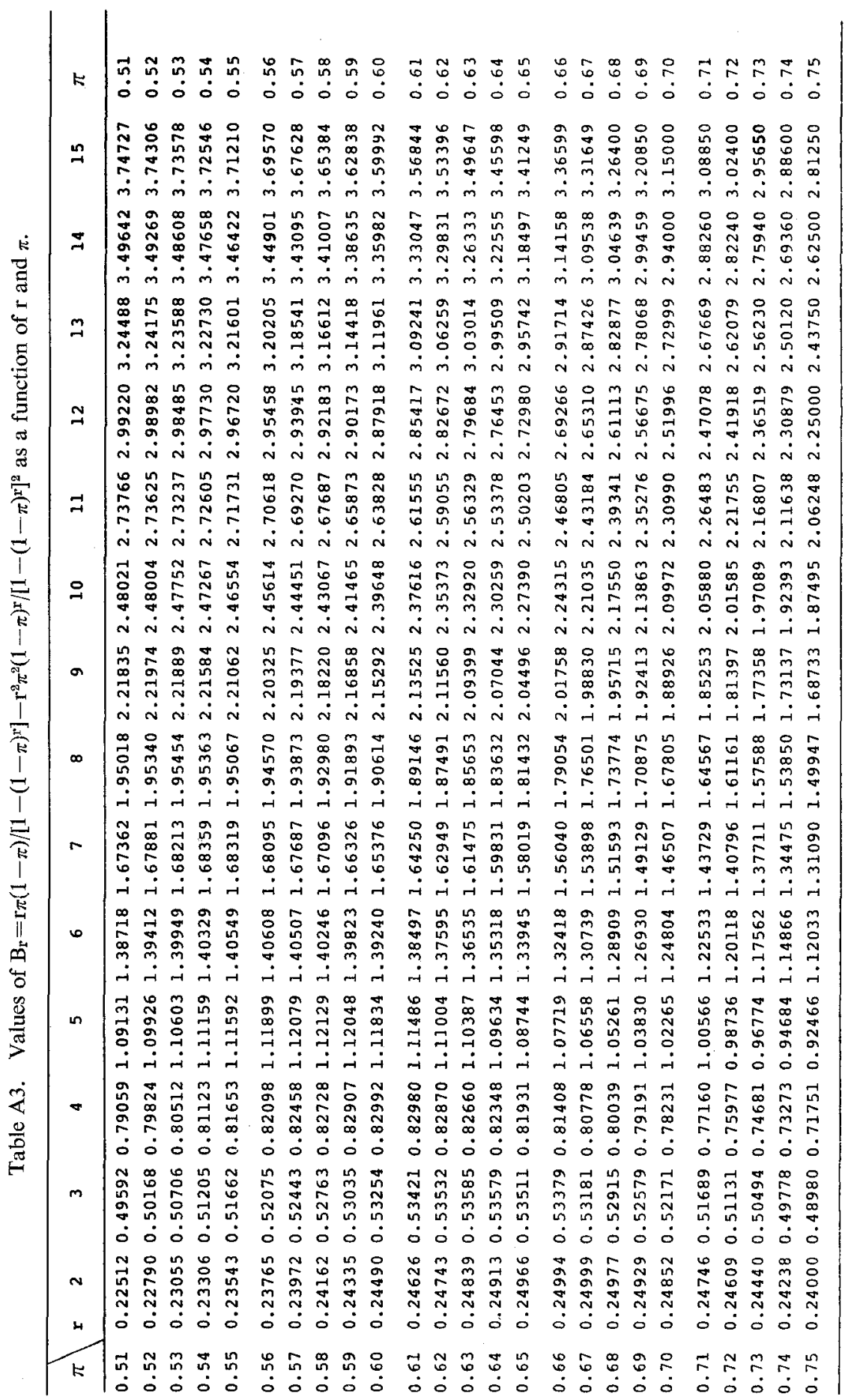




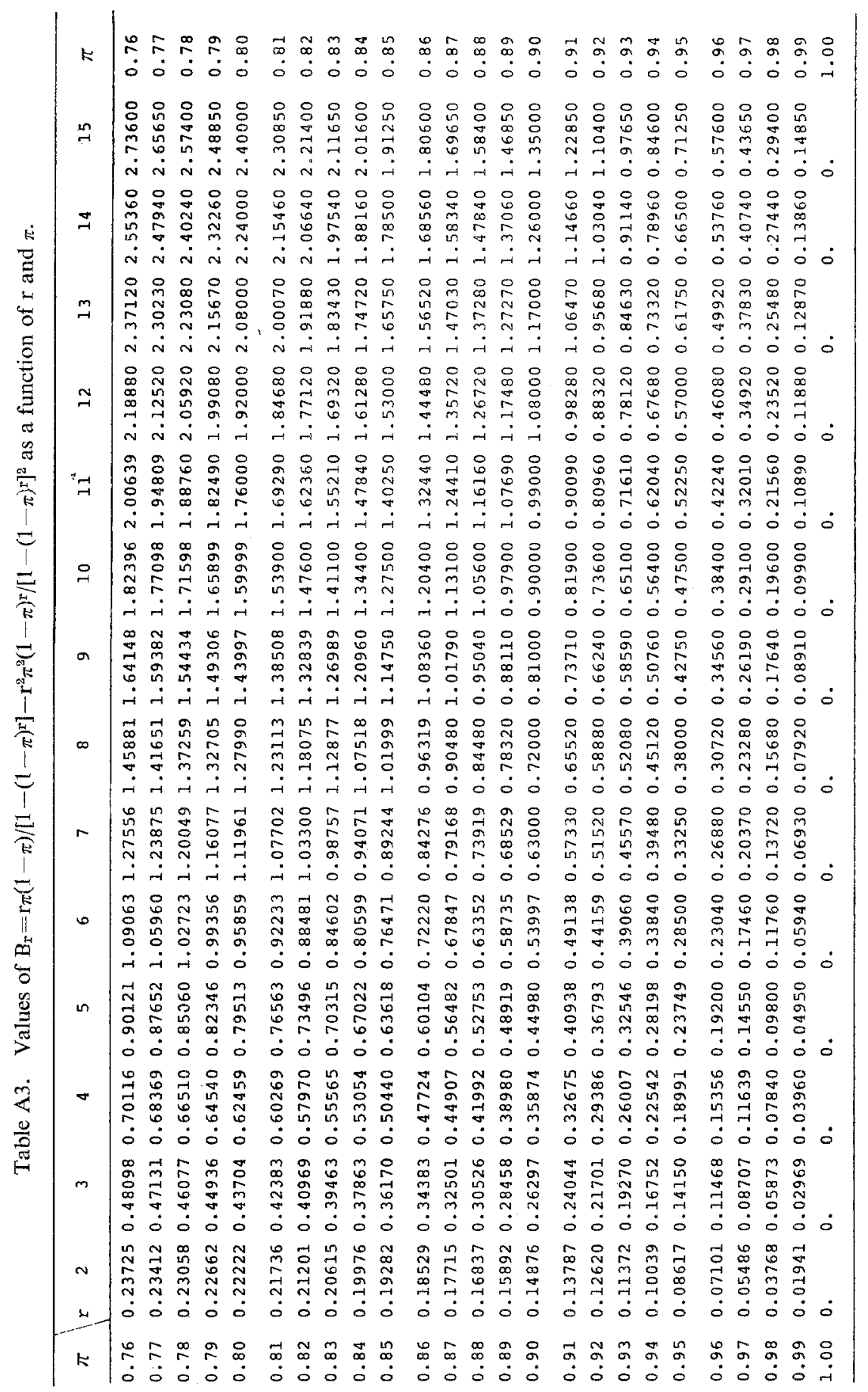


$2.13333 \times 12+2.58065 \times 2+3.04762 \times 1=970.66555$. In Table A3 with $\pi=0.5$, we found $B_{2}=0.22222, B_{3}=0.48980, B_{4}=0.78222, B_{5}=1.08221$ and $B_{6}=$ 1.37868 which yield $\sum_{\mathrm{r}=1}^{6} \mathrm{~B}_{\mathrm{r}} \mathrm{n}_{\mathrm{r}}=0.22222 \times 192+0.48980 \times 39+0.78222 \times 12+1.08221 \times$ $2+1.37868 \times 1=74.69818$. Then, $U=[971-970.66555] /[0.5 \times 0.5]=1.3378$ (from (17)) and $K=74.69818 /[0.5 \times 0.5]^{2}=1,195.1709$ (from (18)). That is, $\hat{\pi}=0.5+$ $1.3378 / 1,195.1709=0.501$ (from (16)) with the standard error $\sqrt{1 / K}=0.029$. Further iterative procedures by computer yielded an estimate in the accuracy of four decimal places as $\hat{\pi}=0.5011 \pm 0.0289$. This is somewhat different from the value in the original text $(0.57)$ which was computed by using the observed K-score, not the expected one as indicated in the present paper. The present method has been proved to be more stable in numerical computation.

Some special cases. When every sibship contains two affected persons $(\mathrm{r}=2)$, one of them is necessarily a proband, or when twins were gathered, the maximum likelihood solution is easily found as

$$
\hat{\pi}=\frac{2 \mathrm{n}_{22}}{\mathrm{n}_{21}+2 \mathrm{n}_{22}} \pm \frac{2 \sqrt{\mathrm{n}_{21} \mathrm{n}_{22}\left(\mathrm{n}_{21}+\mathrm{n}_{22}\right)}}{\left(\mathrm{n}_{21}+2 \mathrm{n}_{22}\right)^{2}}
$$

This is the proband concordance rate for twins (Smith, 1974). For $r=3$ or every sibship bears three affected individuals, the maximum likelihood estimate yields

$$
\pi=\frac{1}{2}\left(3-\sqrt{\left.9-12 \pi_{0}\right)} \pm \sqrt{\frac{\hat{\pi}(1-\hat{\pi})\left(3-3 \hat{\pi}+\hat{\pi}^{2}\right)}{3(3-2 \hat{\pi})\left(n_{31}+n_{32}+n_{33}\right)}}\right.
$$

in which $\pi_{0}=\left(\mathrm{n}_{32}+2 \mathrm{n}_{33}\right) /\left(\mathrm{n}_{31}+2 \mathrm{n}_{32}+3 \mathrm{n}_{33}\right)$ and the following approximation may be practical. That is,

$$
\hat{\pi} \doteq \pi_{0}+\frac{1}{3} \pi_{\circ}^{2} \quad \text { when } \pi_{0}<0.75
$$

These special cases clearly indicate that the estimate of the probability of ascertainment tends to be overrating when the number of simplex proband sibships $\left(\mathrm{n}_{\mathrm{r} 1}\right)$ was ascertained less than expected one. Stated conversely, this is a case when multiple probands in sibship were ascertained of one another not independent way so that $n_{r a}$ 's $(a>1)$ might be inflated. For instance, while medical records are being evaluated in a hospital, a younger brother may be admitted to a hospital for evaluation if his elder brother had already been diagnosed such as Duchenne type muscular dystrophy.

On the other hand, single ascertainment, i.e. $\mathrm{n}_{\mathrm{ra}}=0$ for $\mathrm{a}>1$, obviously yields $\hat{\pi}=0$. Namely, estimate of $\pi$ tends to be underrating. Plausibility of the estimate from sibship material therefore may be examined through a test of goodness of fit. In congenital deaf the independent ascertainments of probands in sibships was in doubt, and in fact the classes of simplex proband $(a=1)$ contributed 56 percent to the total chi-square for a goodness of fit (Table 2). While $\hat{\pi}=0.501 \pm 0.029$ was obtained from all material of Table 2 , multiplex cases alone yielded $\hat{\pi}=0.421 \pm 0.109$ 
Table 2. Ascertainment distribution of congenital deafness in Kanto district (Furusho and Yasuda, 1973).

\begin{tabular}{clrrc}
\hline $\mathrm{r}$ & $\mathrm{a}$ & obs. & exp. & chi-square \\
\hline 1 & 1 & 614 & $-\overline{-}$ & -1.07 \\
2 & 1 & 108 & 127.81 & 6.11 \\
2 & 2 & 84 & 64.19 & 3.23 \\
3 & 1 & 24 & 16.66 & 1.97 \\
3 & 2 & 11 & 16.74 & 0.46 \\
3 & 3 & 4 & 5.60 & 4.57 \\
4 & 1 & 7 & 3.18 & 0.67 \\
4 & 2 & 3 & 4.80 & 0.46 \\
4 & 3 & 2 & 3.21 & 0.81 \\
4 & 4 & 0 & 0.81 & 8.81 \\
5 & 1 & 2 & 0.32 & 1.68 \\
5 & others & 0 & 1.68 & 0.76 \\
6 & 2 & 1 & 0.24 & $35.06^{* * * *}$ \\
6 & others & 0 & 0.76 & \\
\hline
\end{tabular}

$r=$ number of affected sibs.

$a=$ number of probands. $\hat{\pi}=0.501 \pm 0.029$

$* *$ Significant at $0.1 \%$ level $(\mathrm{df}=8)$.

(see the next section) which was not significantly different from the other. Therefore a K-score weighted estimate, $0.49 \pm 0.03$, might be taken as a representative.

Sibship sample of multiplex probands. The geneticist may concentrate on multiplex cases by deliberately excluding sibs with only one affected or he does because there are sibs with two or more affected only. In any case, the probability that there are a probands in selected sibs with $r$ affected is

$$
\mathrm{P}(\mathrm{a}, \mathrm{r})=\frac{{ }_{\mathrm{r}} \mathrm{C}_{\mathrm{a}} \pi^{\mathrm{a}}(1-\pi)^{\mathrm{r}-\mathrm{a}}}{1-(1-\pi)^{\mathrm{r}}-\mathrm{r} \pi(1-\pi)^{\mathrm{r}-1}}(\mathrm{r} \geqq 2)
$$

Note here that duplex sibs $(\mathrm{r}=\mathrm{a}=2)$ yield no information about $\pi$ in this model. The maximum likelihood solution is obtainable from the formulae (16), (17), (18) but in this case

$$
A_{r}=\frac{r \pi\left[1-(1-\pi)^{r-1}\right]}{1-(1-\pi)^{\mathrm{r}}-\mathrm{r} \pi(1-\pi)^{\mathrm{r}-1}}
$$

and

$$
\mathrm{B}_{\mathrm{r}}=\mathrm{r} \pi(1-\pi) \cdot \frac{\left[1-(1-\pi)^{\mathrm{r}-1}\right]^{2}-(\mathrm{r}-1)^{2} \pi^{2}(1-\pi)^{\mathrm{r}-2}}{\left[1-(1-\pi)^{\mathrm{r}}-\mathrm{r} \pi(1-\pi)^{\mathrm{r}-1}\right]^{2}}
$$

(Stene, 1970). Note here that $A_{2}=2$, and $B_{2}=0$. Numerical values of $A_{r}$ and $B_{r}$ are respectively given in appendix for $\pi=0.01$ through 1.00 with the increment 0.01 and for $r=3$ to 15 as shown in Table A4 and Table A5. 


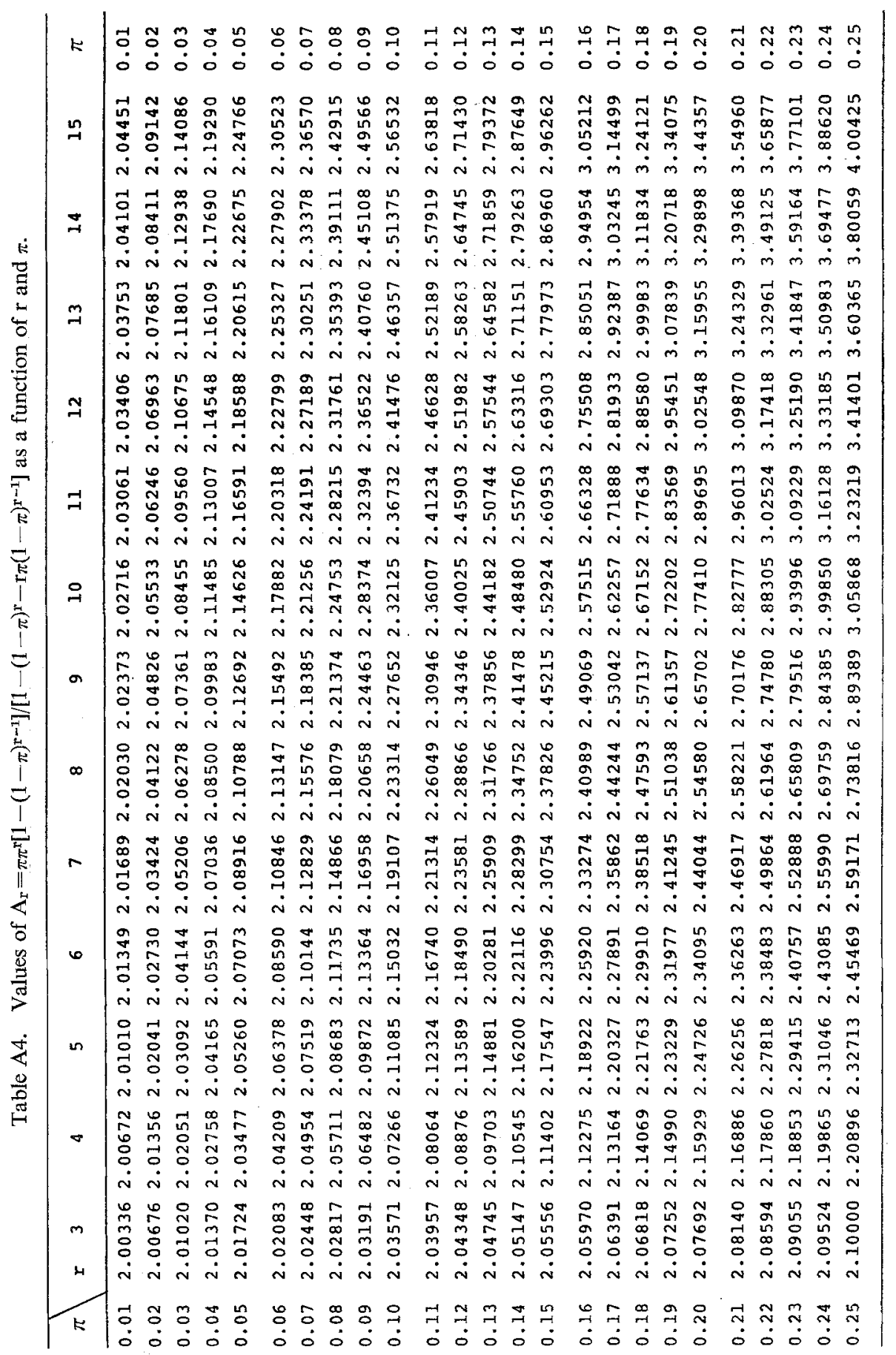




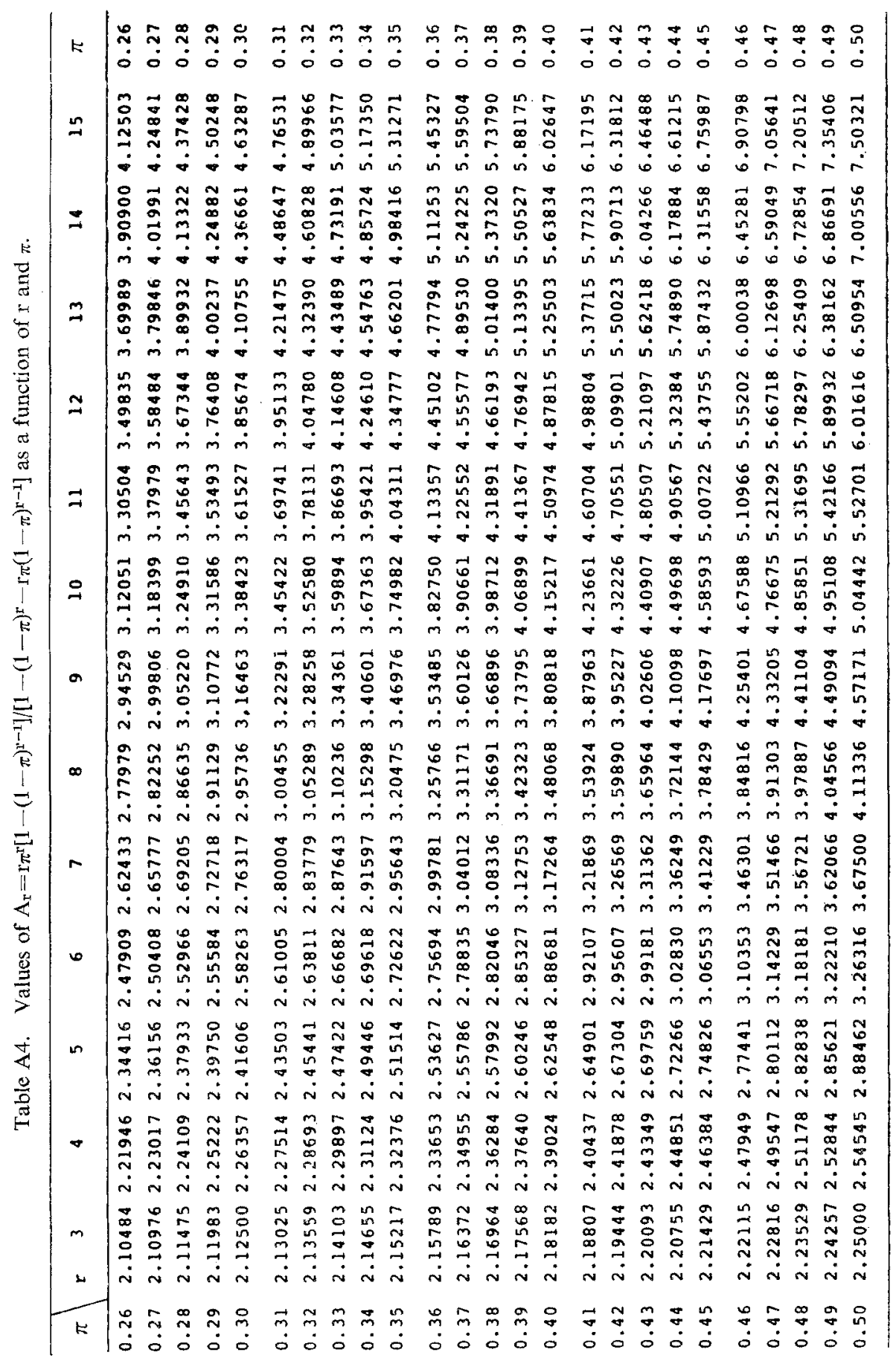




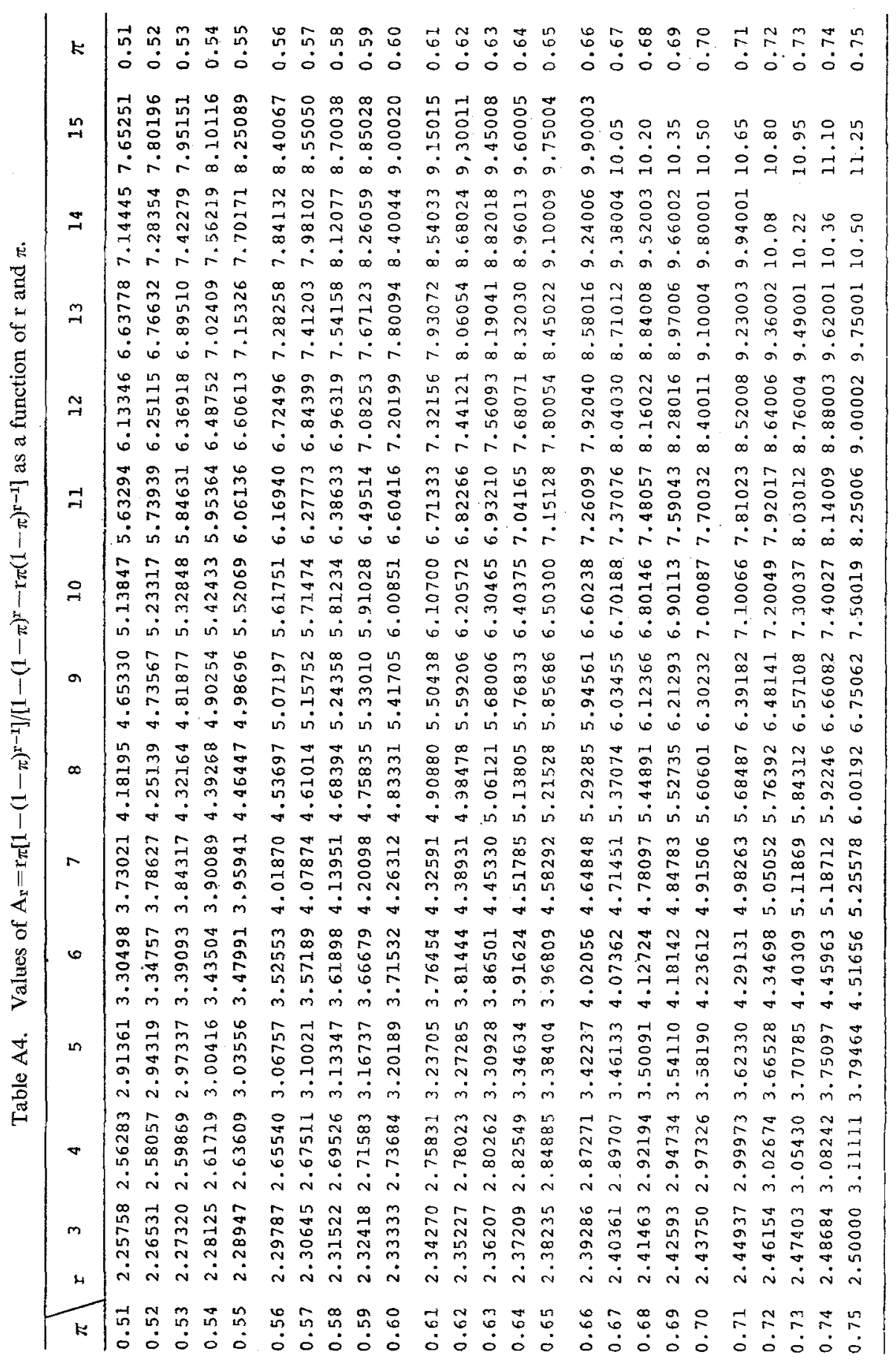




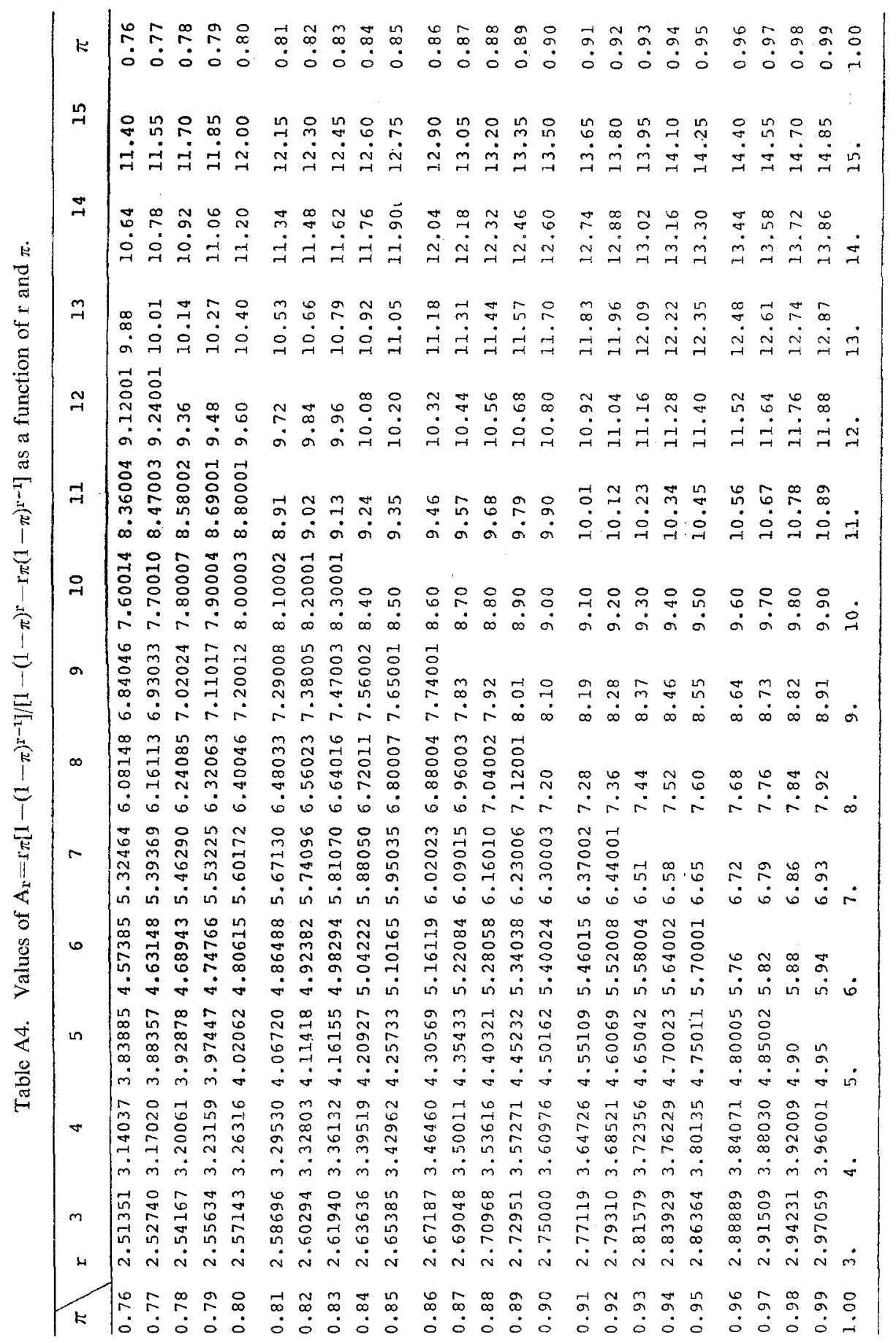




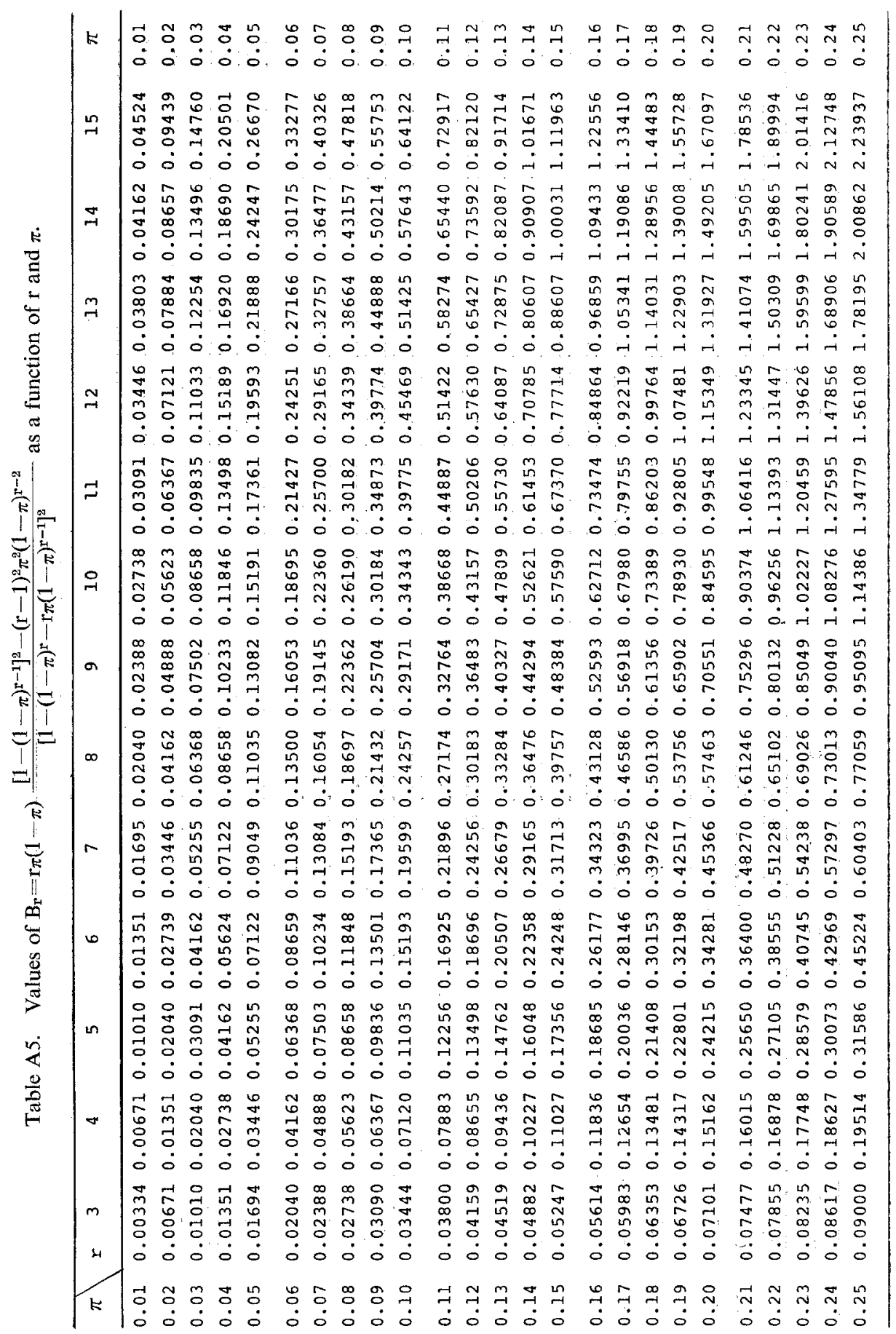




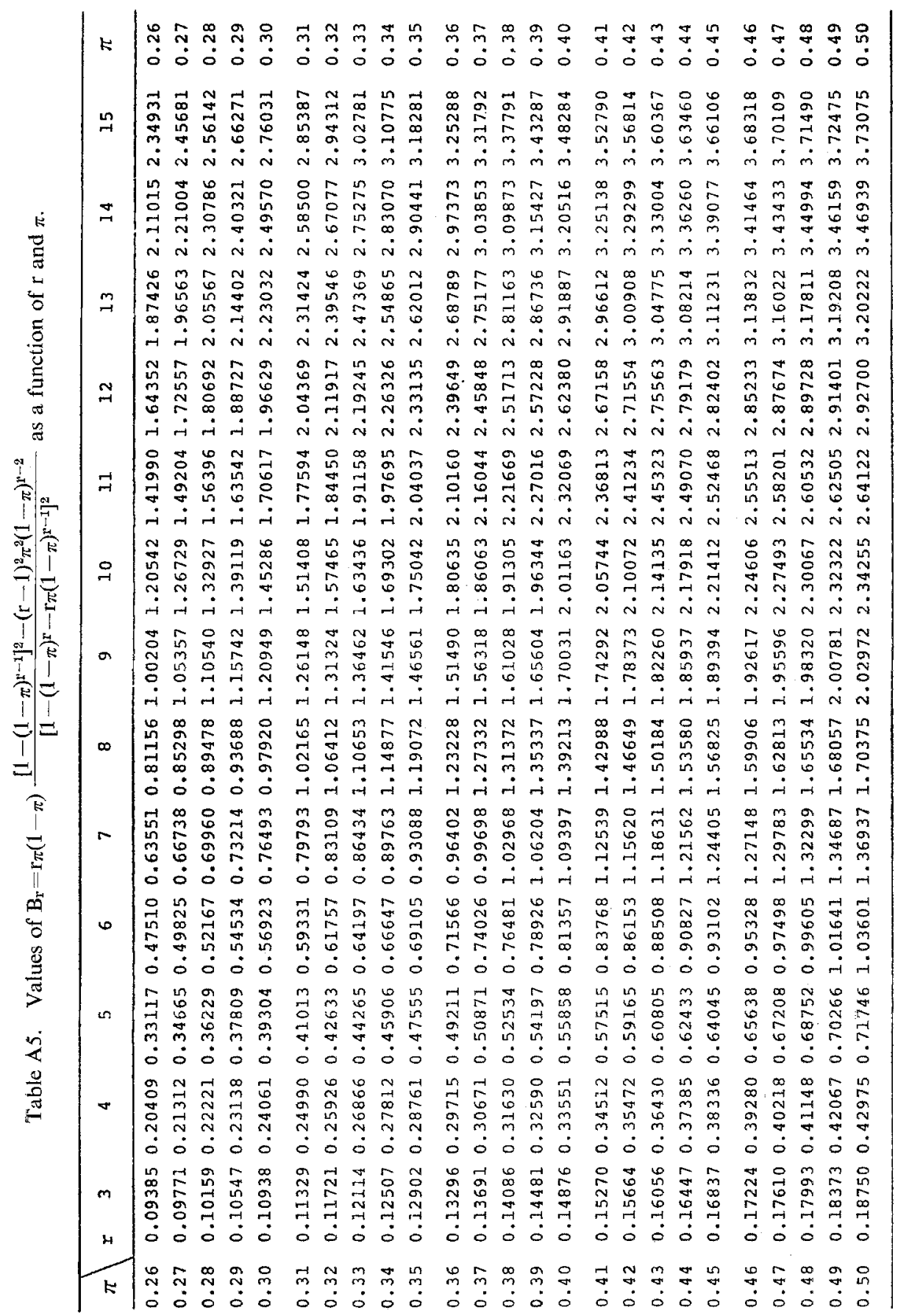




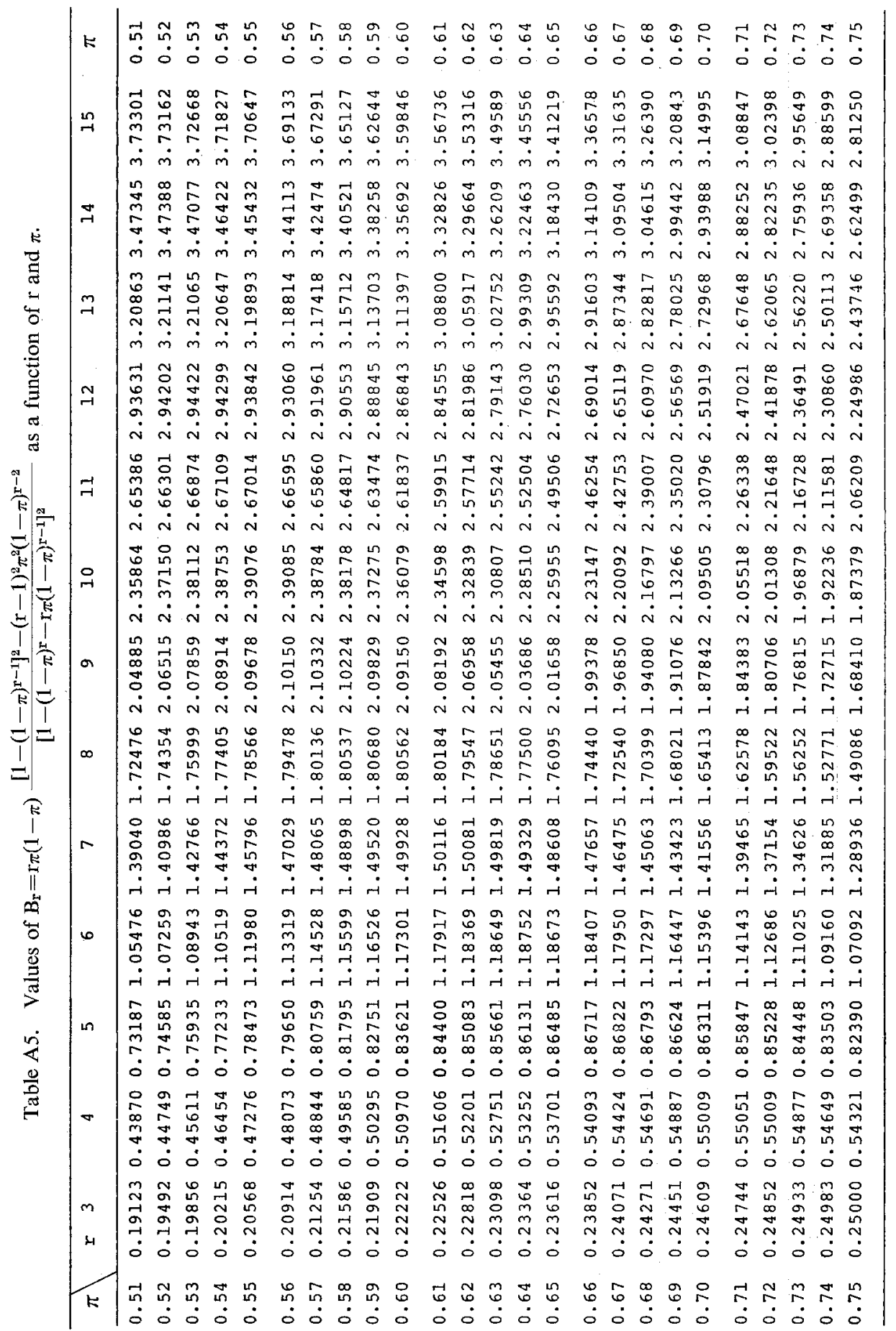




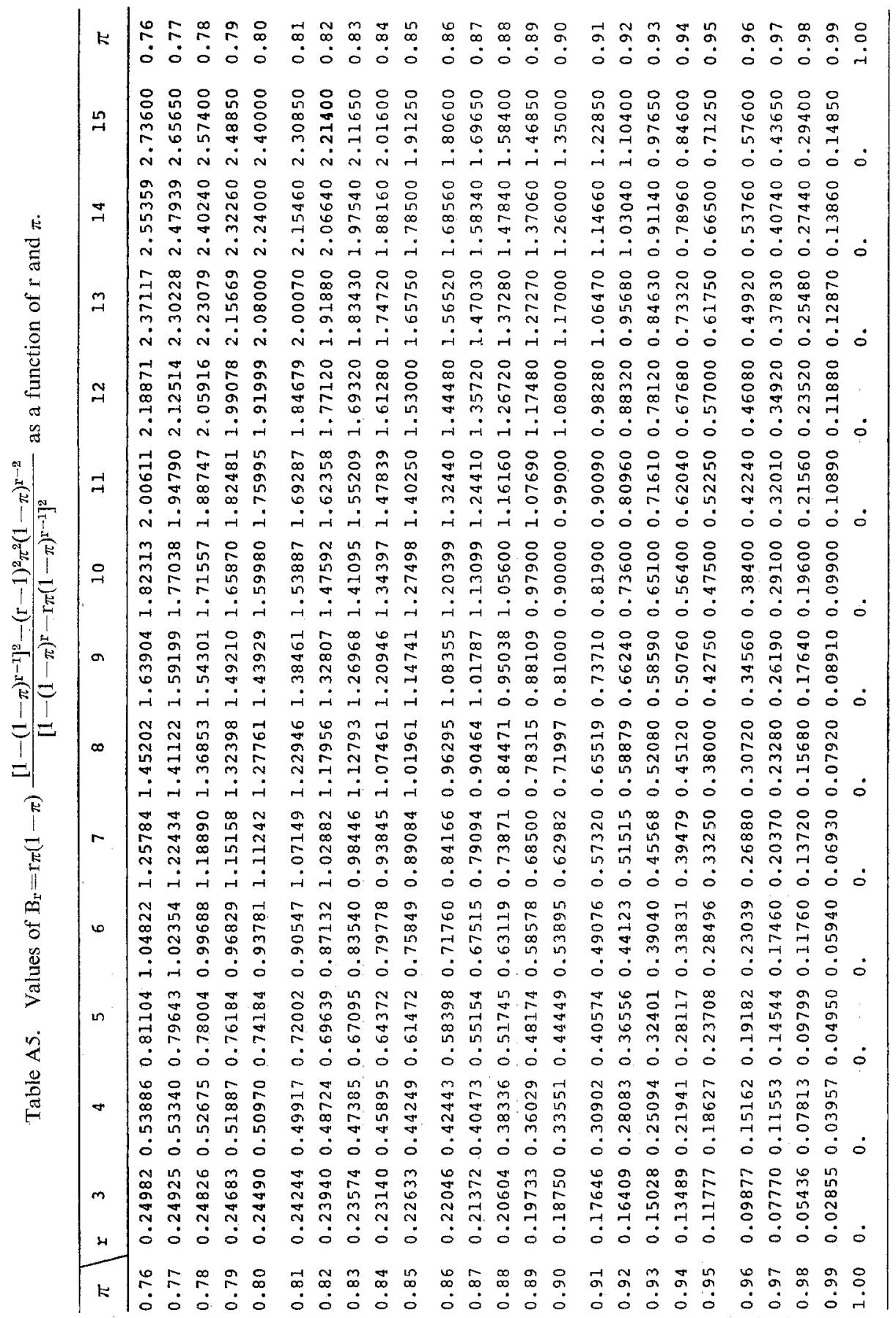


Numerical example. Considering multiplex sibships only in congenital deaf of Table 2, we found $A=216$. With $\pi_{0}=0.5$ we have $A_{3}=2.25000, A_{4}=2.54545$ and $\mathrm{A}_{6}=3.26316$ from Table $\mathrm{A} 4$, and $\mathrm{B}_{3}=0.18750, \mathrm{~B}_{4}=0.42975$ and $\mathrm{B}_{6}=1.03601$ from Table A5. These yield $\sum \mathrm{A}_{\mathrm{r}} \mathrm{n}_{\mathrm{r}}=2 \times 84+2.25000 \times 15+2.54545 \times 5+3.26316 \times 1$ $=217.74026$, and $\Sigma B_{\mathrm{r}} \mathrm{n}_{\mathrm{r}}=0.18750 \times 15+0.42975 \times 5+1.03601 \times 1=5.9973$. Thus we obtain $U=[216-217.7403] /(0.5 \times 0.5)=-6.9601$ and $K=5.99726 /(0.5 \times 0.5)^{2}=$ 95.9562 so that $\hat{\pi}=0.5+(-6.9610) / 95.9562=0.43$. Since the correction term $U /$ $\mathrm{K}=-0.07$ is appreciable, the iterative process is continued taking $\pi_{0}=0.43$, with which we have $A_{3}=2.20093, A_{4}=2.43349$ and $A_{6}=2.99181$ from Table $A 4$, and $B_{3}=0.16056, B_{4}=0.36430$ and $B_{6}=0.88508$ from Table $A 5$. Thus we obtain $U=$ $[216-216.1731] /(0.43 \times 0.57)=-0.70668$ and $\mathrm{K}=85.1446$ so that $\mathrm{U} / \mathrm{K}=-0.01$ yielded $\hat{\pi}=0.42$. By doing so one more cycle, we arrive at $\hat{\pi}=0.42 \pm 0.11$ with $\mathrm{U}=0.1372$ and $\mathrm{K}=84.0015$ from the tables or at $\hat{\pi}=0.421 \pm 0.109$ in accuracy of three decimal places by a computer. In this example, Fisher's formula yields $\pi_{0}=$ 0.83 , being an overestimate in twofold, indicating that the formula (15) might well be inadequate for a data set of multiplex sibs only.

Several models of the ascertainment probability have been developed when $\pi$ 's are variable among sibs (Morton, 1962; 1969). A number of published studies used quite different definitions of proband, but the estimated segregation frequency is reasonably robust with a small variation of $\pi$, but the effect is rather serious on the proportion of sporadic cases. Interested readers should consult to Morton (1969).

\section{DISCUSSION}

The probability of ascertainment is in fact the probability of detection of a single affected person in population and the detections are mutually independent events. For sibship data this probability is interpreted as the probability of inclusion of sibships with at least one affected individual. The probability of detection of sibships with $r$ affected persons is $1-(1-\pi)^{r}$, which is approximately equal to $\mathrm{r} \pi$ when $\pi$ is small. Accordingly, the parameter $\pi$ is certainly related to prevalence.

Barrai et al. (1965) have shown a formula of prevalence as $\mathrm{A} / \pi \pm \mathrm{As}_{\pi} / \pi^{2}$. The rate of prevalence thus become

$$
\mathrm{P}=\left[\mathrm{A} / \pi \pm \mathrm{As}_{\pi} / \pi^{2}\right] / \mathrm{N}
$$

where $\mathrm{A}$ is the total number of probands $\mathrm{s}_{z}$ is the standard deviation of $\pi$ and $\mathrm{N}$ is the size of general population of all ages. In the previous examples prevalence and the rate of it were respectively $1,938 \pm 113$ and $\mathrm{P}=(21.9 \pm 1.3) \times 10^{-5}$ in congenital deaf, and $10 \pm 1$ and $\mathrm{P}=(5.3 \pm 1.1) \times 10^{-5}$ in albino. The sizes of population (N) are respectively taken from demographic year books, 8,845,512 in congenital deaf and 172,273 in albino. Knowledges of population size are crucial in evaluating the rate of prevalence. Size infers to coverage of populations from where 
patients or affected probands are regarded as being randomly taken or independently ascertained. If for instance the probands are defined in terms of medical records at hospital(s), knowledges on community population, especially its size, to whom the hospital serves may be very helpful. Without serious consideration of the size of population, any effort of estimating $\pi$ will be in vain in evaluation of the rate of prevalence. Careful consideration is therefore necessary when we use figures of demographic year book.

The incidence (I) at birth, presumably at conception, of individuals who will develop the trait in question may be obtained from $I=P / d$, where $d$ is an average probability among live births of persons who will become affected if they survive according to the normal life table. Morton and Chung (1959) have shown

$$
\mathrm{d}=\frac{\sum n(\mathrm{a}) \mathrm{p}(\mathrm{a})}{\mathrm{N}}
$$

in which $n(a)$ is the number in the general population at age a and $p(a)$ is the probability that a person capable of developing the trait do so by age a and not die of it before then. For practical purpose $p(a)$ may be approximated by $G(a)[1-D(a)]$ where $G(a)$ is the cumulative frequency of onset of age $a, D(a)$ is the cumulative frequency of death at age a among affected persons. n(a) may usually be found in demographic year books. Hereditary diseases that can be recognized at birth like albino may be considered approximately as $d=1$ so that $I=P$. This however does not hold on the most of the late onset diseases (More precisely disorders which do not manifest the symptoms at birth).

The probability of ascertainment is a nuisance parameter, of no intrinsic genetic interest, in segregation analysis, but there are two reasons why a human geneticist must be concerned with it; evaluation of incidence as discussed already and correction of segregation frequency in order to disentangle the mode of inheritance and the genetic heterogeneity. It is hoped that clinicians who are gathering data of rare diseases should pay more careful attentions in defining proband. Then separation of probands and secondary cases is indispensable and by all means the identification of sources for each proband must be crucial. The estimation of the probability of ascertainment is thus practically feasible with numerical tables provided in this communication.

Acknowledgements I wish to thank Mr. K. Fukuhisa for his technical assistance in running computer programs on TOSBAC 3400 installed in the National Institute of Radiological Sciences. An error in formula (9) was pointed out by a refree to whom I owe.

\section{REFERENCES}

Anderson, V.E. 1961. Statistical studies of probands and their relatives. Ann. New York Acad. Sci. 91: 781-796.

Barrai, I., Mi, M.P., Morton, N.E., and Yasuda, N. 1965. Estimation of prevalence under incomplete selection. Am. J. Hum. Genet. 17: 221-236. 
Elandt-Johnson, R.C. 1971. Probability Models and Statistical Methods in Genetics, John Wiley, New York. pp. 474-475.

Elston, R.C. and Sobel, E. 1979. Sampling considerations in the gathering and analysis of pedigree data. Am. J. Hum. Genet. 31: 62-69.

Fisher, R.A. 1934. The effect of method of ascertainment upon the estimation of frequencies. Ann. Eugen. 6: 13-25.

Fraser, F.C. 1963 . Taking the family history. Am. J. Med. 34: 585-593.

Furusho, T. and Yasuda, N. 1973. Genetic studies of inbreeding in some Japanese populations XIII. A genetic study of congenital deafness. Jpn. J. Hum. Genet. 18: 47-65.

Morton, N.E. 1959. Genetic tests under incomplete ascertainment. Am. J. Hum. Genet, 11: 1-16.

Morton, N.E. 1962. Segregation and linkage. In Methodology in Human Genetics, W.J. Burdette, ed., Holden-Day Inc. San Francisco, pp. 17-52.

Morton, N.E. 1969. Segregation analysis. In Computer Applications in Genetics, N.E. Morton, ed., University Press of Hawaii, Honolulu, pp. 129-139.

Morton, N.E. and Chung, C.S. 1959. Formal genetics of muscular dystrophy. Am. J. Hum. Genet. 11: $360-379$.

Morton, N.E. and Lindsten, J. 1976. Surveillance of Down's syndrome as a paradigm of population monitoring. Hum. Hered. 26: 360-371.

Neel, J.V. 1962. Discussion in Morton, N.E. 1962. pp. 47-52.

Smith, C. 1974. Concordance in twins: methods and interpretation. Am. J. Hum. Genet. 26: 454-466.

Tanaka, K. and Watanabe, K, 1967. Frequency of albino in Japanese population. Jpn. J. Hum. Genet. 11: 231-243.

Thompson, E.A. and Cannings, C. 1979. Sampling schemes and ascertainment. In The Genetic Analysis of Common Diseases: Applications to predictive factors in coronary disease, C.F. Sing and M. Skolnick, eds., Alan, Liss, New York, pp. 363-382. 